\title{
Development of a high temperature treatment device for spent nuclear fuel
}

\author{
Niko Kivel • Natalia Shcherbina • \\ Ines Günther-Leopold
}

Received: 17 July 2012/Published online: 17 August 2012

(C) Akadémiai Kiadó, Budapest, Hungary 2012

\begin{abstract}
Novel reprocessing schemes and techniques are the focus of the Euratom FP7 project "Actinide Recycling for Separation and Transmutation" (ACSEPT), where the Paul Scherrer Institute (PSI) is represented in the pyrochemical domain. The subject of investigation is the selective separation of fission products (FPs) from spent nuclear fuel as a head-end step to either classical hydro based or pyro processes which are not yet applied on a large scale. The selective removal of FPs that are major contributors to the overall radiation dose or bear great potentials in terms of radiotoxicity (i.e. cesium or iodine), is advantageous for further processes. At PSI a device was developed to release volatile FPs by means of inductive heating. The heating up to $2,300{ }^{\circ} \mathrm{C}$ promotes the release of material that is further transported by a carrier gas stream into an inductively coupled plasma mass spectrometer for online detection. The carrier gas can be either inert (Ar) or can contain reducing or oxidizing components like hydrogen or oxygen, respectively. The development of the device by computer aided engineering approaches, the commissioning and evaluation of the device and data from first release experiments on a simulated fuel matrix are discussed.
\end{abstract}

Keywords Inductively coupled plasma mass spectrometry $\cdot$ Reprocessing $\cdot$ Inductive heating

N. Kivel $(\bowtie) \cdot$ N. Shcherbina $\cdot$ I. Günther-Leopold Department of Nuclear Energy and Safety, Paul Scherrer Institute, 5232 Villigen PSI, Switzerland

e-mail: niko.kivel@psi.ch

\section{Introduction}

The radioactive content of spent fuel (SF) and waste generated by the nuclear fuel cycle possesses a potential risk for human beings and the environment. The question of handling these materials continues to be one of the major obstacles to the creation of new nuclear facilities. Up to now large amounts of SF and highly active waste from reprocessing have accumulated worldwide. Therefore, a significant number of studies in the field of nuclear fuel cycle are concerned with management of the radioactive waste to reduce the mass and toxicity of long-lived radionuclides.

Nowadays the concept of a closed nuclear fuel cycle is highly discussed as an alternative to the open fuel cycle to minimize nuclear wastes. A number of strategies have been proposed to adapt already existing techniques for SF reprocessing $[1,2]$. The aim of the novel strategies is to separate unwanted species from the components designated for reuse. In particular the removal of long-lived or volatile fission products, as well as minor actinides like Am or $\mathrm{Cm}$ is critical. Further the separation of $\mathrm{Sr}$ and $\mathrm{Cs}$ is important for safe disposal of high level waste, as they are the main heat-generating nuclides.

At the moment there are two main reprocessing technologies under development: aqueous and pyrochemical (or non-aqueous). In aqueous reprocessing concepts the fuel pins are fed to dissolvers, where nitric acid is used as a dissolution media. This solution is used as an input solution for solvent extraction with tri-butyl phosphate (TBP) in kerosene. A number of aqueous techniques have been developed in the last decades and most of them are based on liquid-liquid extraction: PUREX (used on industrialscale in different reprocessing facilities worldwide), COEX, UREX etc. A more detailed description of 
extraction processes can be found in the Nuclear Energy Agency Report on Actinide Separation Chemistry [3, 4].

The non-aqueous processes are based on the molten salt technology and may include voloxidation, FLUOREX and pyro-reprocessing. Recent studies have repeatedly demonstrated that the use of non-aqueous technologies can potentially reduce plant sizes and waste volumes due to the high concentrations that can be handled without the criticality constraints inherent to aqueous systems. Voloxidation implies fluorination of SF and separation of $\mathrm{U}, \mathrm{Pu}$ and $\mathrm{Np}$ from other materials based on their fluoride volatility. Pyro-reprocessing employs a molten salt electrorefining process and results in selective deposition of actinides onto the cathode [5-7].

Recently an alternative way of FP partitioning from SF was proposed by the Paul Scherrer Institute that contributes with a number of other laboratories to the development of head-end steps for reprocessing technologies in the framework of the ACSEPT project. The emphasis is put on the development of thermal and thermochemical treatment procedures of SFs with the aim of partitioning the FPs from $\mathrm{U}$ and transuranium elements into the gas phase promoted by inductive heating (Inductive Vaporization).

This paper describes the design and the implementation of a high temperature Inductive Vaporization device (InVap). In particular the boundary conditions leading to the final design of the device are reported. A demonstration on a non-irradiated material is given as a proof of concept.

\section{InVap design and operational parameters}

The heating of radioactive material to very high temperatures with the direct detection of the released material by means of inductively coupled plasma mass spectrometry (ICP-MS) was the goal of the design process. The boundary conditions where set by the researchers before the technique was chosen. The actual design of the InVap was carried out in a computer aided engineering (CAE) approach. In this approach definition of boundary conditions is followed by the selection of the best candidate technique for the given purpose. After the technique is selected, a 3D model is created and optimized by modeling of various free parameters like gas flows in the apparatus and comparing the maximum feasible temperature to the design goal. The following requirements were predefined for the device:

- Maximum sample temperature $>2,000{ }^{\circ} \mathrm{C}$

- Ramping of the temperature with heating rates as low as $10{ }^{\circ} \mathrm{C} \min ^{-1}$

- Capability to handle SF
- Inert, oxidizing (for pre-oxidation) and reducing gas atmosphere

- Direct connection to an ICP-MS

\section{Evaluation of candidate techniques}

In order to meet these criteria laser heating, electrothermal vaporization and inductive heating were assessed. Since emission of infrared light is the dominating effect at temperatures $>2,000{ }^{\circ} \mathrm{C}$ the power loss due to radiation had to be considered. This excluded the heating by laser, because the power loss would demand a rather powerful and costly laser or requires an infrared reflector in the close vicinity of the sample.

For electrothermal vaporization a graphite tube, holding the sample, is heated by the Joule effect. The commercially available devices are designed for pulse operation rather than for slowly increasing the power over a long time. A very high electrical current is necessary to heat the graphite tube. Moreover, the sample handling is hampered by the fact that the sample has to be placed on the L'Vov platform in the graphite tube. For this procedure the tube has to be removed from the furnace and later carefully be realigned, that might cause a problem of contamination when irradiated fuel is treated.

The technique selected as the most promising candidate was inductive heating of the sample in a graphite crucible. Inductive heaters are available in nearly any power range and the shape of the load coil can be freely selected. Further, the load coil can be covered with silver to act as a reflector for the infrared radiation. The devices are designed for continuous operation at full power and can ramp the power at almost any rate.

\section{Material selection}

The materials for the device were carefully selected since they have to withstand high temperatures but may not interact with the inductive heating, except the crucible. As a cavity wall in the high temperature zone a quartz tube (30 mm ID) was selected. Quartz can withstand temperatures of $>1,000{ }^{\circ} \mathrm{C}$ at almost full mechanical strength and is not prone to thermal shock. A window, also made from quartz, was placed in the lid as an observation port for temperature measurement. To support the crucible a ceramic pillar $(\mathrm{MgO})$ was selected. The material has a maximum working temperature of $2,400{ }^{\circ} \mathrm{C}$ and does not interact with the high frequency field. The base and the lid of the device are made from aluminum because of its good machining properties. 


\section{Computer aided engineering (CAE) design}

After defining the working conditions and the suitable materials, a first design study was performed. In this study the limitations in terms of heat radiation as well as interaction of metallic components with the high frequency field were already considered. The manufacturer of the load coil limited the maximum ID of the coil to $35 \mathrm{~mm}$ which was considered by selecting an appropriate quartz tube. Limitations from the mechanical point of view were considered as well as the availability of standard parts like gas connectors, O-rings or quartz windows. The mechanical design was performed with AutoDesk Inventor 2010 in 3D. The result of the first design study is shown in Fig. 1. Based on the study a testbed prototype consisting only of the base, the quartz tube and the insulation pillar was produced in the workshop.

The testbed was used to determine the gas temperature above the crucible, which was necessary to design the lid of the device and to benchmark the finite element modeling results obtained by the ANSYS/FLUENT software. The temperature of the Ar flowing around the crucible was determined close to the end of the quartz tube to be $400{ }^{\circ} \mathrm{C}$ at maximum forward power, which is in good agreement with simulations. Based on the rather high temperature of the gas, a quenching with a second gas stream was implemented which reduced the temperature to approximately $250{ }^{\circ} \mathrm{C}$ (Fig. 2). The injection port position was optimized with ANSYS CFD to achieve good mixing of

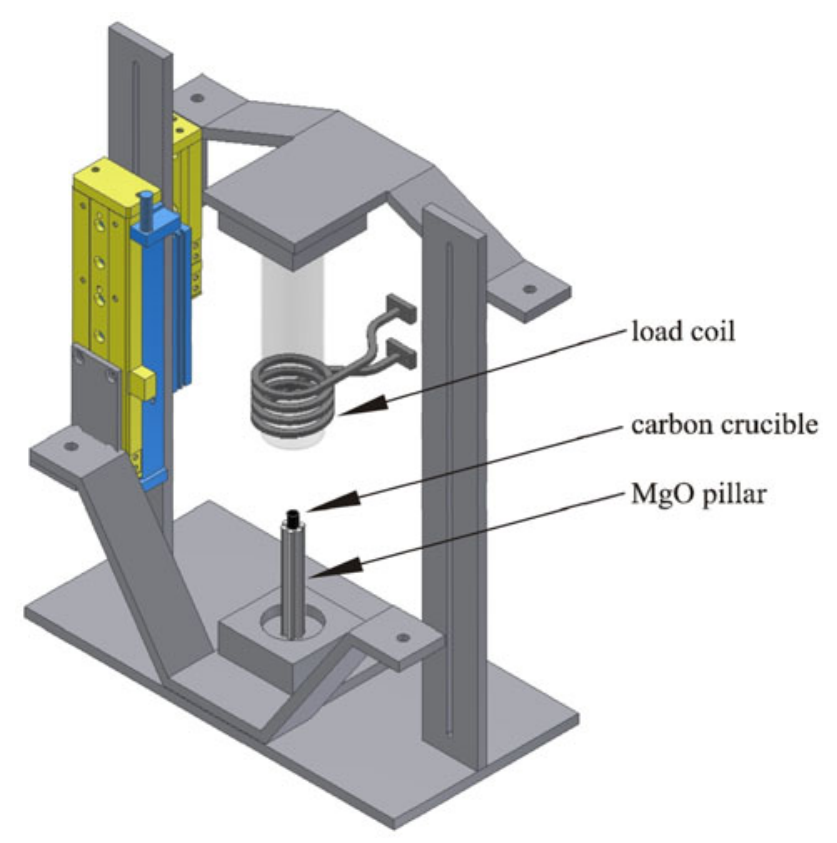

Fig. 1 3D-Model of the first design study of the InVap device. The total height of the device is about $40 \mathrm{~cm}$. The quartz tube has an OD of $3 \mathrm{~cm}$

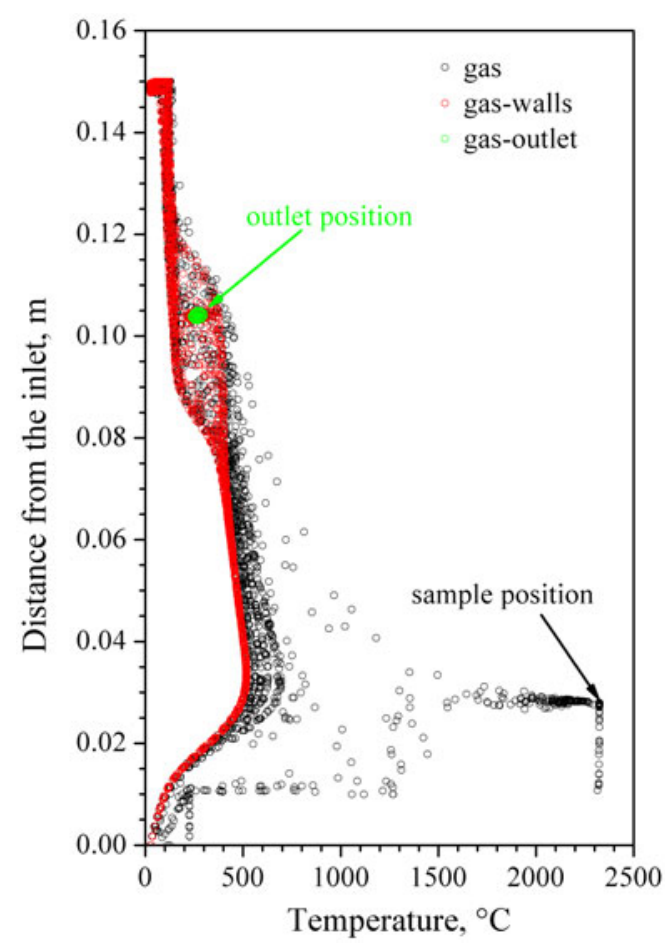

Fig. 2 Temperature data from the ANSYS/FLUENT simulation. In red the gas temperature at the wall boundary. In green the temperature at the outlet, and in black (for a selection of nodes) the temperature in the void volume, is plotted. (Color figure online)

the high and low temperature gases before exiting the device.

\section{High frequency equipment}

The load coil of the inductive heater is made of silver plated copper with a rectangular cross section and has an ID of $35 \mathrm{~mm}$. The silver plating acts as an infrared mirror that reflects most of the emitted radiation back onto the crucible. The coil is positioned at the same level as the carbon crucible containing the sample and is directly connected to the high frequency matching network. The matching network itself is connected to the generator (TNX5 compact, Plustherm Point GmbH, Wettingen, Switzerland) which provides the $105 \mathrm{kHz}$ high frequency.

\section{Control mechanism}

The heater is operated in an open control circuit, meaning no feed back from the pyrometer is used for the control. To provide the user with a convenient means of operating the device, a software frontend was programmed in LabView. The software enables the user to select heating profiles of 
virtually any kind, only constrained by the maximum heating and cooling rate of the crucible.

\section{ICP-MS coupling}

In order to couple the InVap to the ICP-MS the void of the device has to be flushed with a carrier gas (Ar). The total carrier gas stream consists of a sub-stream at a low flow rate of $0.3-0.5 \mathrm{~L} \mathrm{~min}^{-1}$ that enters at the base and flows around the crucible. This sub-stream can be mixed with air or a hydrogen/argon mixture to adjust for oxidative or reductive atmosphere. A second argon stream at a flow rate of $0.6-1.0 \mathrm{~L} \mathrm{~min}^{-1}$ is introduced beneath the quartz window to quench the hot carrier gas and prevent the contact of the released material with the window to avoid condensation. The ICP-MS (Element 2, Thermo Fisher, Bremen, Germany) is connected via a $2 \mathrm{~mm}$ ID PTFE tubing from the lid of the InVap. Between the InVap and the ICP a cyclonic spray chamber can be installed to introduce an element in liquid form to account for possible changes in the plasma conditions.

\section{Final setup and implementation}

During the final installation and qualification, the testbed was completed addition of the lid and the pyrometer to assemble the system as depicted in Fig. 3. The figures of merit of the InVap, like the maximum heating or the ramping of the temperature, were determined. All predefined conditions were met or exceeded. The maximum achievable temperature is around $2,300{ }^{\circ} \mathrm{C}$, exceeding the design criterion by $15 \%$. A summary of the technical data is provided in Table 1.

First long term heating tests revealed that the high temperature gradient in the ceramic pillar caused cracking due to thermal tension: this issue could be circumvented by stacking two crucibles on each other to reduce the temperature gradient in the insulating pillar. To prevent degradation of the o-rings sealing the quartz-aluminum interface, the metallic parts were equipped with channels for cooling water. Cooling with $20{ }^{\circ} \mathrm{C}$ water was found to be sufficient.

The pyrometer, used to measure the sample temperature, has a limited measurement range of $750-2,500{ }^{\circ} \mathrm{C}$. The lack of a temperature measurement device for temperatures below $750{ }^{\circ} \mathrm{C}$ made a cross calibration of power to crucible temperature necessary. The calibration was established by extrapolation of the high temperature measurements toward lower temperatures as shown in Fig. 4. It was not possible to measure the temperature of the crucible directly, e.g. with a thermo couple, because the measurement device would be heated by the high frequency, which

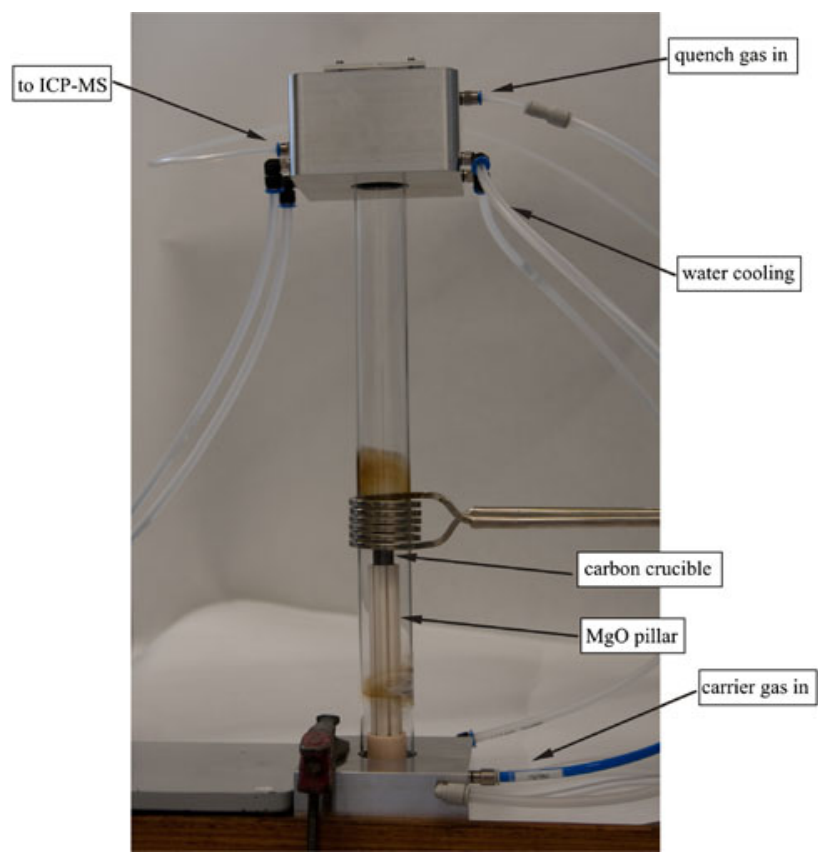

Fig. 3 Photograph of the assembled InVap device. The length of the quartz tube is $35 \mathrm{~cm}$, with an OD of $3 \mathrm{~cm}$

Table 1 Technical data of the InVap device

\begin{tabular}{ll}
\hline Parameter & Value \\
\hline High frequency & $105 \mathrm{kHz}$ \\
Forward power & $100-7,500 \mathrm{~W}$ \\
Maximum heating rate & $200{ }^{\circ} \mathrm{C} \mathrm{s}{ }^{-1}$ \\
Maximum temperature & $2,300{ }^{\circ} \mathrm{C}$ \\
Maximum time at full power & Infinite \\
Cooling $\left(2,000-750{ }^{\circ} \mathrm{C}\right)$ & $45 \mathrm{~s}$ \\
\hline
\end{tabular}

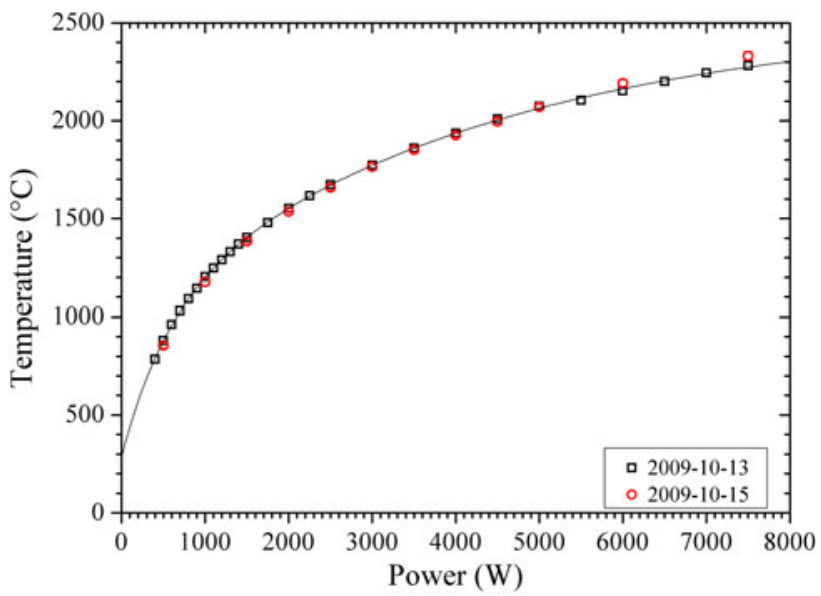

Fig. 4 Calibration of the temperature with the forward power of the inductive heater: red and black markers represent two independent experiments. (Color figure online) 
Fig. 5 Transient signal for a selection of elements during an InVap experiment with SIMFUEL. The signals are normalized to the highest signal to account for different signal strength

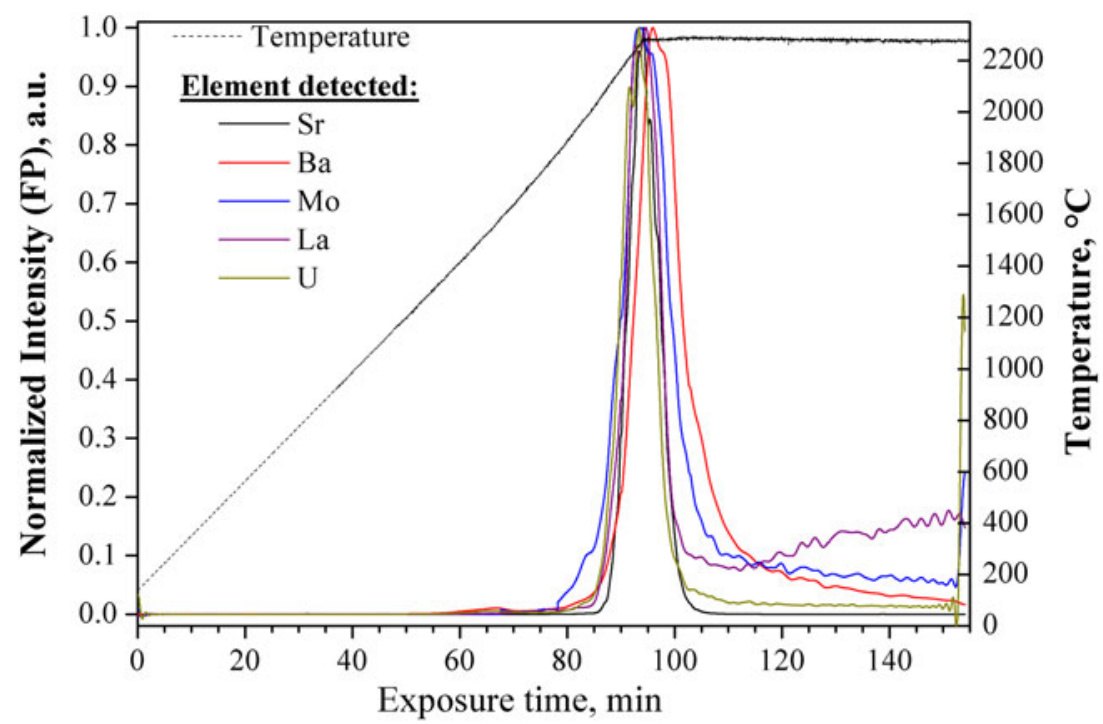

would lead to biased results. The possibility of installing a second pyrometer for the lower temperature range was considered, but rejected because it would make the InVap design much more costly and complex.

As final step of the installation and qualification period the InVap was connected to the ICP-MS and a non-irradiated material simulating spent nuclear fuel (SIMFUEL) $[8,9]$ was introduced. It was possible to detect the release of important fission products like $\mathrm{Sr}$ and the lanthanides, as well as $U$ from the matrix. The time dependent response of the mass spectrometer for a selection of elements is presented in Fig. 5.

\section{Conclusion and outlook}

It was shown that a device for the high temperature treatment of SF with online detection by ICP-MS can be based on inductive heating. The use of modern CAE-techniques significantly reduced the time of the design process and helped to reduce costly and time consuming production of prototypes. Not a single part had to be machined twice or was discarded due to design flaws.

The InVap was used for some 200 experiments since its installation under all predefined conditions. The results are used in the EURATOM FP7 Project ACSEPT to improve the flow-sheets for future concepts of SF reprocessing.

Acknowledgments This research project has received funding from the European Atomic Energy Communities 7th Framework
Programme under grant agreement no. FP7-CP-2007-211267, the ACSEPT project. The effort of the workshop personnel, especially Marcus Keller and Andreas Spahr, is greatly appreciated.

\section{References}

1. Del Cul GD, Spencer BB, Collins ED (2005) Hybrid processing of spent fuel. Proceedings of Global conference

2. Del Cul GD, Hunt R, Spencer BB (2004) Advanced head-end processing of spent fuel. American Nuclear Society Winter Meeting

3. Ozawa M, Koma Y, Nomura K, Tanaka Y (1998) Separation of actinides and fission products in high-level liquid wastes by the improved TRUEX process. J Alloy Compd. doi:10.1016/ S0925-8388(98)00147-9

4. Nuclear fuel reprocessing (2010) Idaho National Laboratory (INL) http://www.osti.gov/energycitations/product.biblio.jsp?query_id=1 \&page $=16 \&$ osti_id=974763. Accessed 17 July 2012

5. Brand GE, Murbach EW (1965) Pyrochemical reprocessing of UO2 by AIROX. Atomics International, Canoga Park

6. Laidler JJ, Battles JE, Miller WE, Ackerman JP, Carls EL (1997) Development of pyroprocessing technology. Prog Nucl Energy. doi:10.1016/0149-1970(96)00007-8

7. Malmbeck R, Nourry C, Ougier M, Souček P, Glatz JP, Kato T, Koyama T (2011) Advanced fuel cycle options. Energy Procedia. doi:10.1016/j.egypro.2011.06.013

8. Lucuta PG, Verrall RA, Matzke Hj, Palmer BJ (1991) Microstructural features of SIMFUEL-Simulated High-Burnup UO2-based nuclear fuel. J Nucl Mater. doi:10.1016/0022-3115 (91) $90455-\mathrm{G}$

9. Lucuta PG, Verrall RA, Matzke Hj, Hastings IL (1992) Characterization and thermal properties of hyperstoichiometric SIMFUEL. Proceedings of 3rd International Conference on CANDU Fuel 